\title{
GNOSTIC VIEW IN CONTEMPORARY ISLAMIC ARCHITECTURE (IN CASE OF ARDALAN)
}

\author{
AGHAEI RAD, Hamid \\ $\mathrm{PhD}$ candidate in University of New South Wales \\ PO Box 259, Paddington, NSW 2021, AUSTRALIA \\ Email: hamid.aghaeirad@unsw.edu.au
}

\begin{abstract}
This paper argues that essentially Nader Ardalan has tried to enrich contemporary architecture of his time with his understanding of traditional Islamic architecture. Consequently, this paper pays attention to Nader Ardalan's works and thought. This article generally points to the relationship between idea and practice to preserve traditional Islamic architecture and in particular, it demonstrates the influence of the ideas of Ardalan's book, The Sense of Unity: The Sufi tradition in Traditional Persian Architecture (1974), on his projects. This article particularly concludes that despite the rise of technology of construction and modification of context and eco-social forces which are apparent over the three decades of design, the principles of traditional Islamic architecture can be identified conceptually within Ardalan's projects to differing degrees.
\end{abstract}

Keywords: Tradition and modernity; modern technology and conceptual principles of islamic architecture.

\section{INTRODUCTION}

\section{Who is Ardalan?}

Nader Ardalan (1939-Tehran) is an Iranian architect who graduated from Harvard University. Fundamentally, Ardalan's reputation in Iran is based on his projects. Ardalan participated in design process of more than 112 projects across the world but his global reputation is largely based on his work as a scholar within the society of traditional architectural researchers (Masud, 2009). However Ardalan often has been introduces as "an architect with a long and distinguished international career in the fields of planning, architecture and historic preservation [additionally, as] a recognized world leader and expert in the field of environmentally sustainable and culturally relevant design with a particular focus on Islamic countries" (Ardalan's resume).

Ardalan's most celebrated book is The Sense of Unity: Traditional Persian Architecture (1974), cowritten with Leleh Bakhtiar. Early on his career he became a founding member of the Steering Committee of the Aga Khan Award for architecture and has maintained a proactive approach to revive traditional and Islamic architectural practices. As of February 2014, he is the Harvard university graduate school of design senior research associate where he co-directs the "Gulf Encyclopaedia for Sustainable Design" (Ardalan, 2009).

It is pertinent to note that Ardalan as an architect and a scholar has "practically and philosophically encountered the issues of traditional architecture and its potential integration within the contemporary context," (Ardalan, 1980) however most Islamic scholars of architecture have not engaged with these practical issues. Thus both sides of his professional life are closely related but deserve individual attention.

\section{Ardalan as Scholar; The Sense of Unity}

Ardalan and his co-writer Bakhtiar are highly acclaimed for this book because it presents new attitudes towards Islamic architecture (Ardalan, 1980). Regarding the significance of the attitudes of the authors in Sense of Unity Seyyed Hosssein Nasr has written: "until now [1973] [Islamic art] has been only too rarely studied with the aim of understanding its symbolic and metaphysical significance" (Nasr, 1973). In fact, Sense of Unity tries to redefine the basis of Islamic Architecture with respect to the doctrine of Sufism. Ardalan and Bakhtiar's approaches to Islamic architecture can be seen as participating in the same line of thinking as Burckhardt (1976) and Akkach (2005), who have emphasised the symbolic language and meaning of Islamic Architecture.

In Sense of Unity the authors explore the concept of unity in traditional architecture and identify how the concept of unity resonates throughhout traditional architecture. Although unity is a principle of Islam, it is not over emphasized rather, unity of religion is indicated and results in the term 'spiritual architecture' instead of 'Islamic architecture'. Spiritual architecture is not the only term 
created by the authors. 'Creative Man' is another new term Ardalan and Bakhtiar introduced into Islamic architecture. They argue that "because Man, the microcosm, is the mirror image of macrocosm, ${ }^{i}$ he contains all the possibilities of the universe within himself .... Man is the pivot between the arc of descent and ascent" (Ardalan and Bakhtiar, 1973). Consequently Ardalan and Bakhtiar assume that traditional Man was able to create a balance between the invisible and visible world. This role of traditional Man has not been emphasized in Islamic architectural studies before Sense of Unity. Based on this assumption the Sense of Unity demonstrates the following concepts as the principles of traditional Islamic Architecture: sense of place; the continuity of positive space; the idea of 'zahir'ii (manifested) and 'batin' 'iii (hidden) and more importantly centrality and central ordering systems.

\section{Ardalan as an Architect}

Ardalan's work is represented internationally most numerously in the Middle East and America. Interestingly different functions such as residential, office, stadium, university, museum and art centre are addressed in his projects. In an overview a specific frame work cannot be identified for these projects. Some of them look modern and while others are admired due to their incorporation of traditional symbols. Similar tension has appeared in his inspirational sources. While Ardalan in an interview says that he was influenced by Corbusier's work when he was a student at Harvard, but over time he has been inspired by Louis Kahn (Ardalan, 2014).

\section{RESEARCH METHOD}

This article pays attention to Ardalan's projects and tries to analyse his selected projects based on the main ideas of the Sense of Unity in order to make clear the relationship between ideas and practice in the light of traditional Islamic architecture and in the case of Nader Ardalan.

Since this paper brings together Ardalan's theoretical understanding of Islamic architecture and his design principles, Ardalan's projects will be categorized from their relationship with Ardalan's scholarly character. Consequently Ardalan's oeuvre can be divided into three parts. Prior to Sense of Unity; the immediate Sense of Unity and post Sense of Unity (Ardalan, 2013).

A compression between projects in the second and third periods makes clear the impact of modern conditions on the relationship between theory and practice over time. Of most interest are: the Univer- sity of Imama Sadiq or Iranian Centre of Management Studies (ICMS) (Tehran, Iran) from the second period and the College of Information Technology (Al-Ain, Emirate) from the third period of practice. ${ }^{\text {iv }}$

\section{ANALYSES}

\section{The University of Imam Sadiq or ICMS}

The university of Imam Sadiq or Iran Centre of Management Studies has been selected for study due to its importance in contemporary Islamic architecture. In 1989 it was proposed for an Aga Khan Award because of Ardalan's endeavour to revive traditional architectural principles. While an award was not forthcoming, the technical review published by the Aga Khan Institute commented favourably that: while the ICMS project did not use any direct formal element nor decorative traditional motifs, its connotations to tradition were more spatial, morphic, syntactic, symbolic and abstract (Ardalan, 1989).

The first phase of this project was offered to Farmanfarmaian and Associates when Nader Ardalan was its partner in the autumn of 1970 and the second phase was taken up by Ardalan's own firm, The Mandala Collaborative, in May 1973. The first phase was completed in September 1972 and the centre opened with only 60 resident students. It was enlarged in 1974 to 120 students with the completion of the second phase (Ardalan, 1989).

This complex contains a main courtyard which is in fact a big garden $\left(80^{*} 130 \mathrm{~m}\right)$ and a library which is located in the middle of the garden. The library garden functions as a courtyard for the units. In traditional Islamic architecture, courtyards were included in residential buildings and also in Madras (college in Islamic and traditional sense) to keep these spaces quieter and private. These features have been achieved in this project by arranging the units around the courtyards. In this complex each unit consists of 5 chambers which are arranged in a concentric order around a small courtyard.

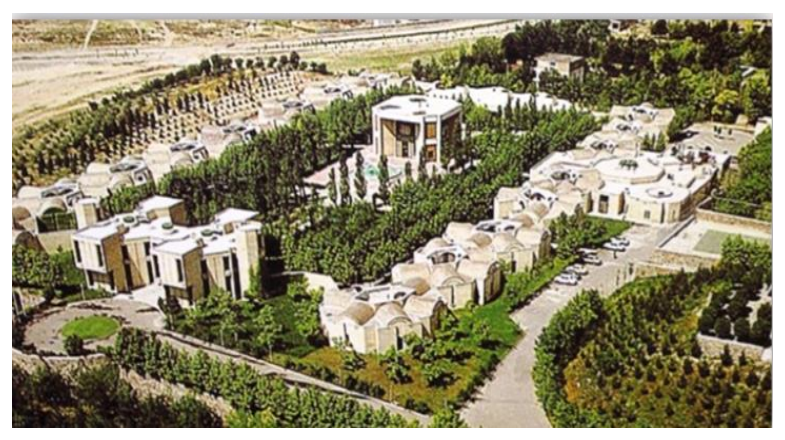

Figure 0. ICMS (picture from University of Imam Sadiq) 


\section{Relationship Between Sense of Unity and the ICMS}

While Ardalan claims that the design principles of ICMS are based on the ideas in Sense of Unity such as zahir and batin, positive space continuity and spatial order, these concepts are without clear explanation (Ardalan, 1989). However what can be identified in the ICMS are concepts such as centrality, unity, macrocosm and microcosm and traditional order making systems. Accordingly By looking at Ardalan's projects, sketches and site plans it is possible to see the relationship between the ideas expressed in Sense of Unity and his buildings

\section{Concept of Centrality and Unity}

From a sophist perspective, a central point of a circle is symbolic of the Divine manifestation at a timeless moment. In sacred geometry "the circle surpasses all other geometric patterns as the symbol of cosmic unity, its inner core or hidden centre becoming the timeless moment of the revolutions of time and the dimensionless point of the encompassing space" (Critchlow, 1976). Therefore the inner core of the circle shows the primordial presence of the Divine and consequently the circle embodies the reality of the Divine presence and its unity. In fact the circle is the state of first determination (Akkach, 1990).

This model of centrality is expanded into the bigger scale. Each unit contains a central point and surrounding points are arranged around the centre in small scale and this patterning is repeated in the whole complex a large scale. Entire units are points around the library which is the central point of complex. It means the sense of unity unfolds both in the small and large scales. In addition each unit or module is repeated in the floor plan of the entire complex. The existence of 24 inscribed octagons inside circles confirms modularity. Moreover this similarity and the repetition of units emphasize symbolically the meaning of unity and multiplicity. ${ }^{\mathrm{v}}$

Furthermore, Ardalan has emphasized the idea of centrality by using the concept of inwardness in the units on a small scale and on a large scale in the garden (fig. 1). In the university design process he said "what better symbolism for the idea of centrality, of inwardness?" (Kassarjian and Ardalan, 1989). Thus this project clearly shows centrality by its being inward looking. This centrality culminates in the units (fig. 2). As initial sketches of this project illustrate, the floor plan of each unit is chambered on concentric circles. Obviously these concentric circles introduce their common centres and Ardalan has placed a tree on the central point of the courtyard of each unit to unfold these hidden points for viewers (fig. 3).

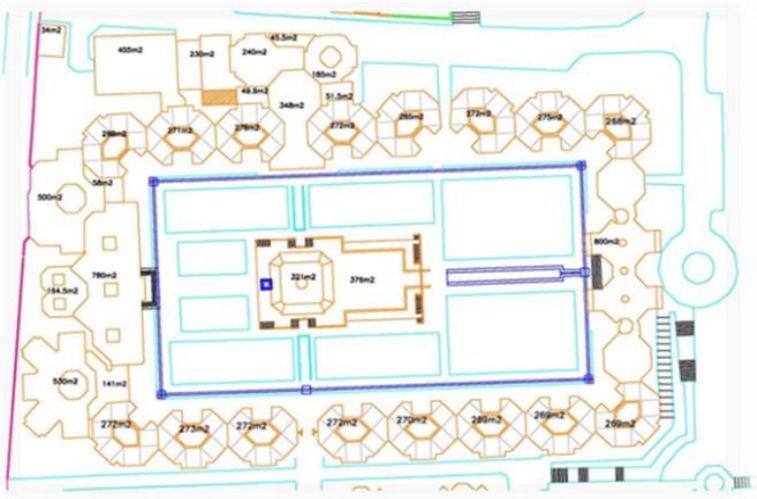

Figure 1. ICMS Site plan

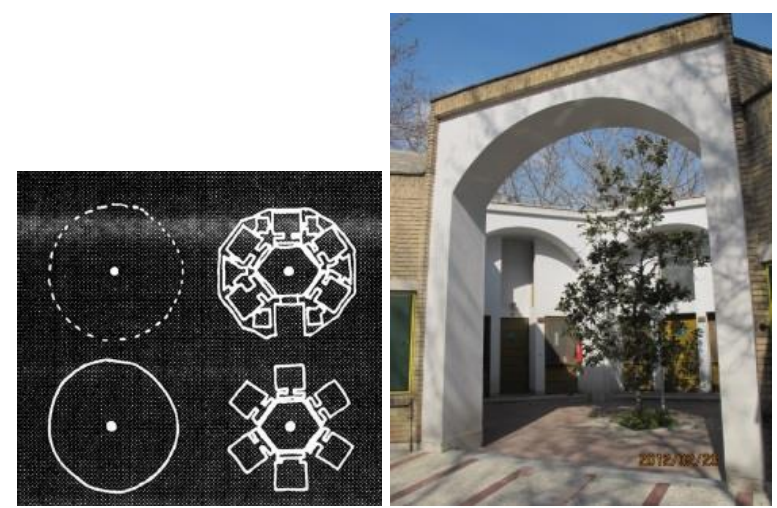

Figure 2. Centrality in Units

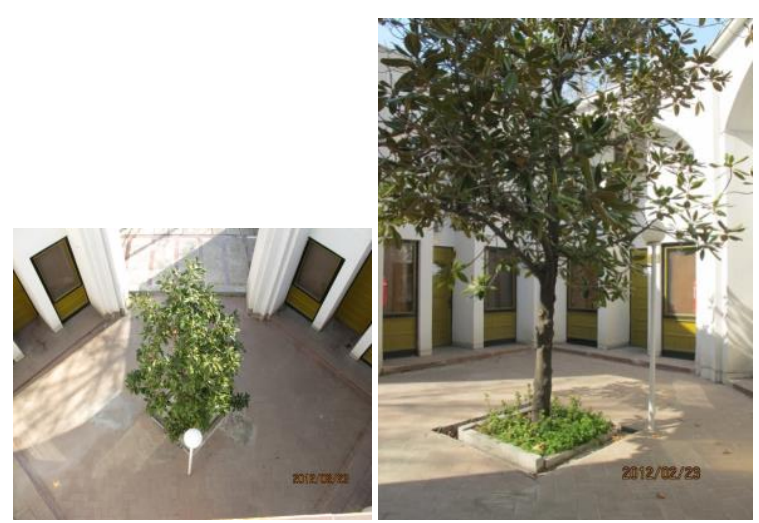

Figure 3. Central points in units

According to Ardalan's sketches, an octagonal is inscribed in the biggest circle with 8 common points. Consequently the second stage of drawing a unit's floor plan comprises a central point and its connections (radiuses) with 8 points on a locus circle (fig. 4). In Sufism a sense of a circle and its centre and radius reveal the Divine relationship with man and also unfolds the unity of the creator and creatures. Moreover this ternary (centre, radius and circumference) symbolizes the first comprehensible form of unity and multiplicity and also the relation between knower (the essence), known (the names) and knowledge (connections) (fig. 5). 


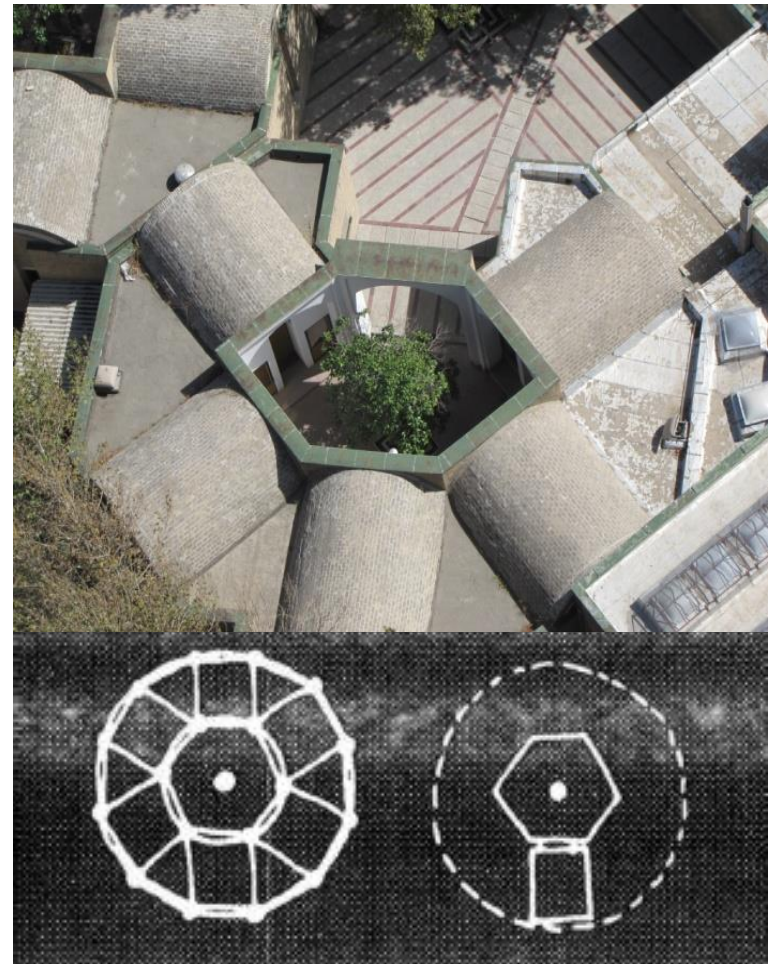

Figure 4. Radiuses in units

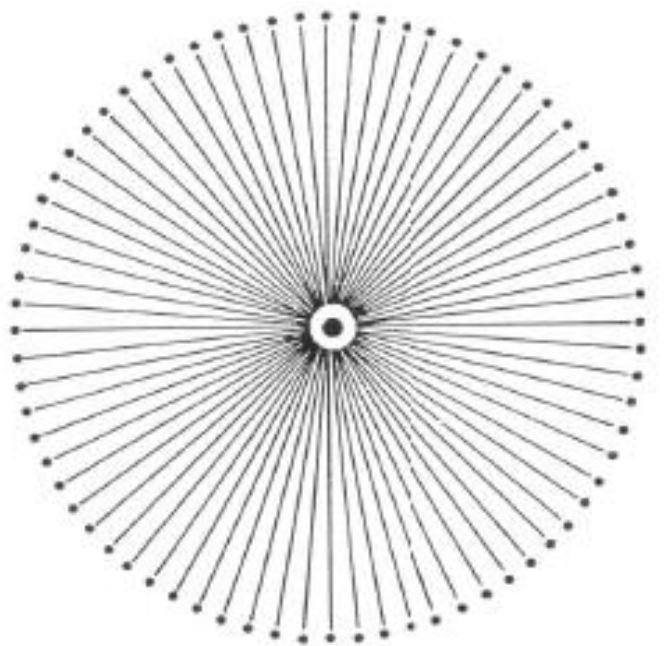

Figure 5. Symbolic relationship between the Divine and universe in Sufism

Centrality is not limited to traditional Islamic architecture. Centrality is incorporated in many traditional architectures (Fung, 1982). However Ardalan uses centrality as part of his understanding of Islamic architecture. A point as a main part of centrality is the most important principle of geometry in both sensible and intelligible realms. "As the principal point is the progenitor of space, the geometric centre is the generating principle of figures" (Fung, 1982). Therefore "Every traditional architectural form that functions as a symbol has a centre; geometrically and spatially the building expands from a point" (Snodgrass, 1990) . This trend is an imitation of the production of the world of multiplicity from unity, so the significance of the central point is its cosmic aspect. In other words the centre of every space equates to the original essence of the universe.

\section{Microcosm and Macrocosm}

As discussed above, Ardalan has been inspired by both the traditional garden-yard of residential buildings and the palace gardens in Iranian traditional architecture (Kassarjian and Ardalan, 1989). He has successfully combined two diametrically opposed practices of inward and out ward looking. Thus there are two perspectives: an inward looking- ness and also an outward looking- ness into the main court yard which depends on a viewer's location, standing either in the library or standing in a unit. In other words the library building and its surrounding yard is outward looking while the units are inward looking buildings (fig. 6).

For Ardalan, the reason for the inward and outward integration is not limited to traditional Iranian architecture, but as he acknowledges in The Sense of Unity there are two types of motives with each direction: one is of earth, corporeal, outward to the enveloping heavens (macrocosm); and the second is of physical presence; its inward direction is toward the hidden treasure that is the seat of Divine spirit (microcosm). Consequently the university contains both symbolism of the microcosm and the macrocosm just as "the universe is composed of a microcosm and a macrocosm" (Ardalan and Bakhtiar, 1973) .

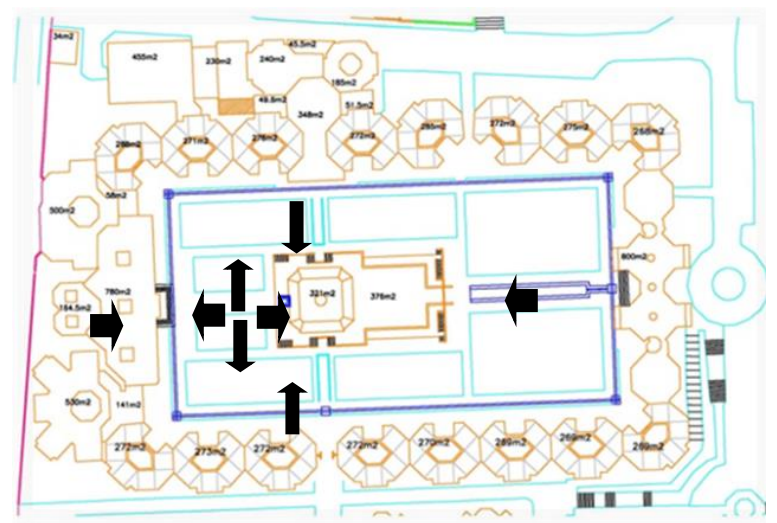

Figure 6. Combination of inward and outward looking

\section{Order Making Systems}

Another link between The Sense of Unity and ICMS is concerned with the order making system. 
Concentric and linear systems which are discussed comprehensively in the book are evident in the spatial arrangement of the ICMS. Since all spaces in the units and also in a larger scale all units in the entire architectural complex are arranged around centres, they reflect the concentric order that express "the principle of sacred pattern in a static manner" (Akkach, 2005). From another perspective, arranging units along with a straight line presents a linear order that "expresses the principle of the sacred pattern in a dynamic manner" (Akkach, 1990). Each side of the main court yard is based on the linear order (fig. 7). The best traditional example for this type of ordering is a Bazaar. A Bazaar is composed of several units (modules) that are approximately similar to each other in a linear order and "they are formed by the repetition of a spatial units, creating a number of individual concentric spaces" (Akkach, 1990).

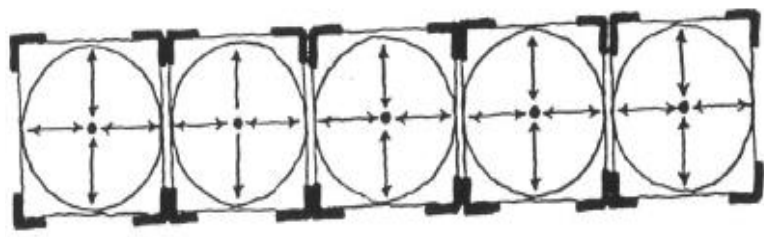

Figure 7. Linear order system

\section{College of Information Technology (CIT) Back- ground and Architecture}

To find a sense regarding the architecture of this college it has to be said that the CIT was designed in 2002 for a student population of 3000 . This four storey building is located approximately in the middle of the university's site and exactly on the main axis. The building mass houses a variety of functions including reception, prayer halls, cafeteria and student lounges at ground level and classrooms and labs on other levels. The floor plan of CIT is an oval $(120 \mathrm{~m}$ by $80 \mathrm{~m}$ ) with a core at its middle. Surrounding the core is an atrium ( $32 \mathrm{~m}$ by $32 \mathrm{~m}$ ) which is lit naturally through its roof. A wide pathway divides the mass into two parts and connects the atrium to the exterior. Several glass and steel bridges connect the core and two parts of the building to each other and in fact complete the circulation on the top floors (fig. 8).

\section{Modern Technology and Traditional Pattern}

Concrete, steel or their combination are used in his projects but a square grid has been often used which can make the structure easily constructible and economic (Ardalan, 2002). Generally architecture that fulfils its direct utilitarian purpose and no other is based on the idea of fundamentalism and consequently modernism.

Structure is exposed in the first generation of buildings. While in the CIT, except for trusses, the structure is clad in finishing materials. Generally exposing or hiding the structure in Ardalan's projects relates to the prevalent architecture of the time. In fact Ardalan has attempted to follow the international (contemporary) styles of his time.

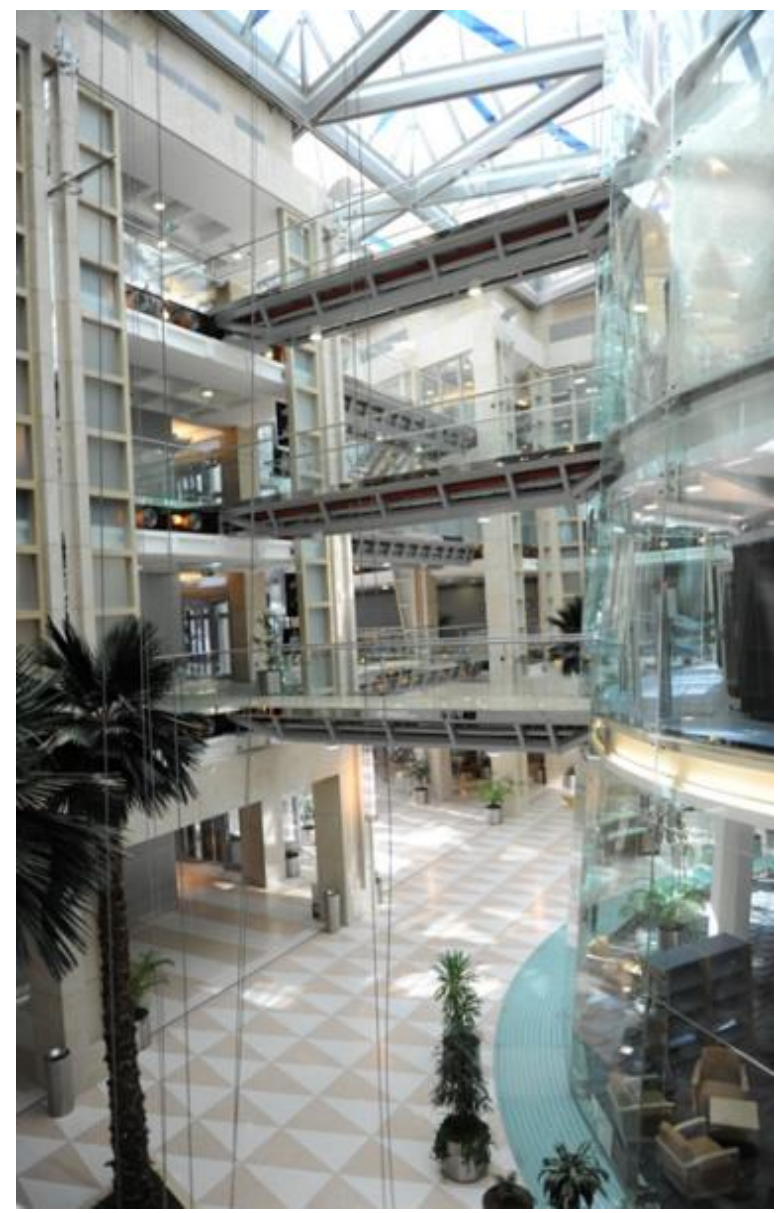

Figure 8. Bridges for completing circulations over the atrium (picture from University of Al-Ain)

Ardalan's use of finishing materials and ornamentation are typical of modern architecture: first, similar to the prevalent modern architecture in the region, the façade is independent of the floor plans with panoramic windows. Second, wide curved glass with very precise (fine) joining indicates the application of a high technology (fig. 9). Using high technology is not limited to the size of the glass panels. "The outer skin of the rotating spiralling ellipse evolved as a transparent veil built in high performance glass, using heat mirror technology and south façade shading through solar cell screens" (Ardalan, 2002). 


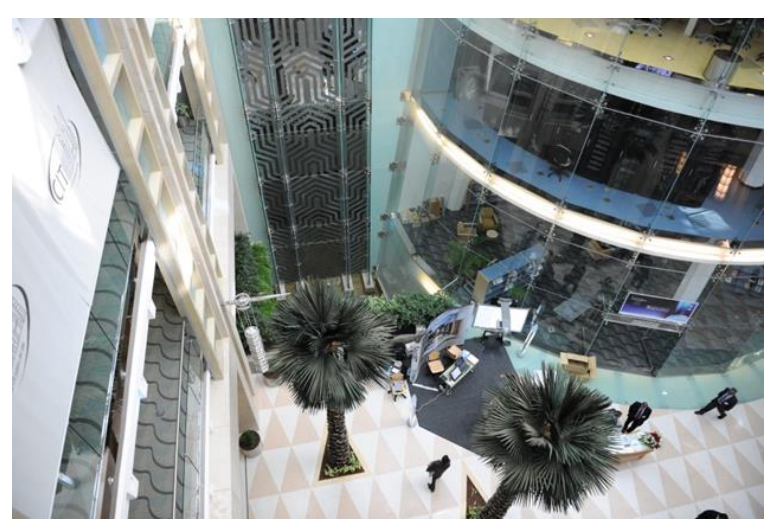

Figure 9. Wide curved glass (picture from University of Al-Ain)

Not only the façade, but also the ornamentation in this project bears no similarity to other projects. There are two main differences between ornaments in this project and Ardalan's first generation of projects. First, ornaments can rarely be seen in the first generation work. Second, Islamic or traditional patterns are used in the ornaments of the CIT. For example: tiles with engraving "ALLAH" are used for decoration. And also as Ardalan (2002) notes that a geometric shape used for the inside façades is inspired by a traditional pattern which is typically found on ancient pottery in $\mathrm{Al}$ Ain (fig. 10).

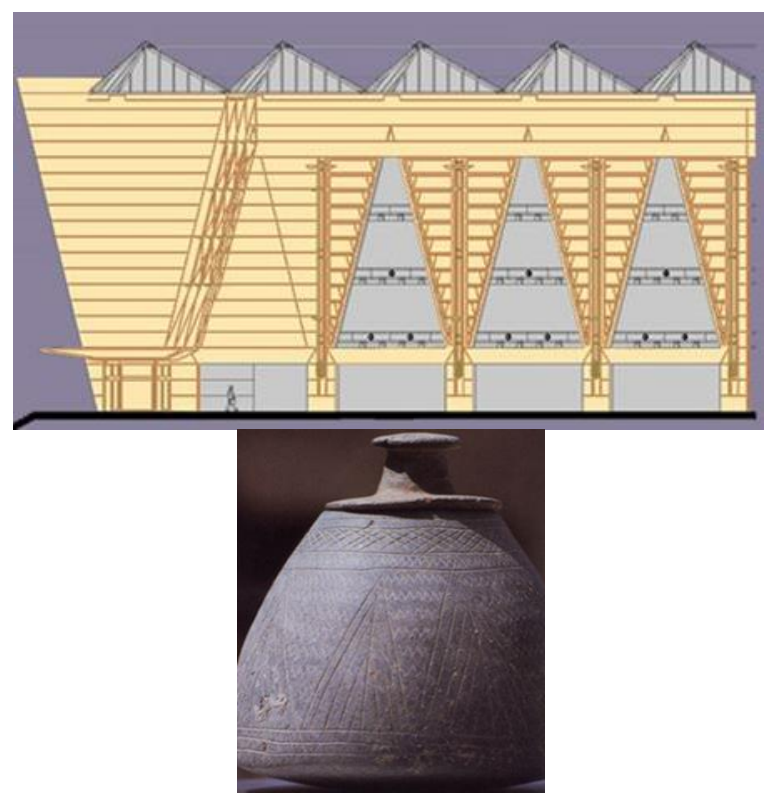

Figure 10. Traditional pattern in CIT (KEO, 2002)

\section{Repeating Geometric Shapes and the Concept of Courtyard (Ardalan's Architectural Principles)}

Among these differences, geometric shapes are the common point between the CIT and other projects. Geometric shapes particularly a circle and a square are frequently used in the CIT's floor plans. Perhaps Ardalan has been following a specific purpose by repeating usage of these shapes. His purpose can be identified in the light of the ideas of Sense of Unity.

Interestingly, even in geometry there are two differences between the CIT and other projects which can be seen in organizing geometric shapes in the floor plans. First, the outer shell in the CIT does not depend on the interior spaces and their shapes. While in his first generation of work there is not any outer shell. In fact in those projects there is a reciprocal relationship between the total shape of the block and interior shapes. This is seen in the ICMS. Interior walls in octagonal shapes around the courtyard are concentric like radiuses of a circle (fig. 11). While in the CIT although the outer line is elliptic, the interior walls are not concentric and spaces limited by exterior walls are deformed (fig. 12). Second, all projects of the first generation are more or less symmetric. At least asymmetry cannot be understood by viewers in the buildings. However in the CIT, the pathway which divides the mass into two parts is a bit off the main axis of the elliptic. It seems that Ardalan tried to disturb the symmetrical planning arrangement of the CIT at the last stage of its design process.

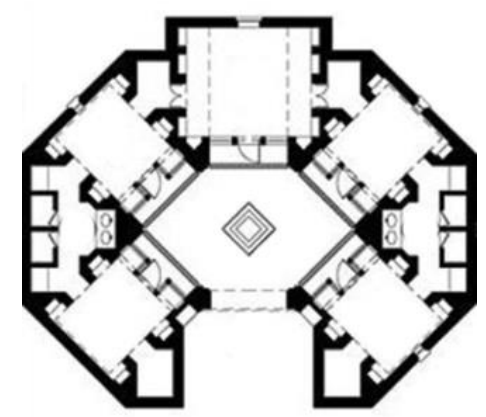

Figure 11. Units' floor plan of the ICMS

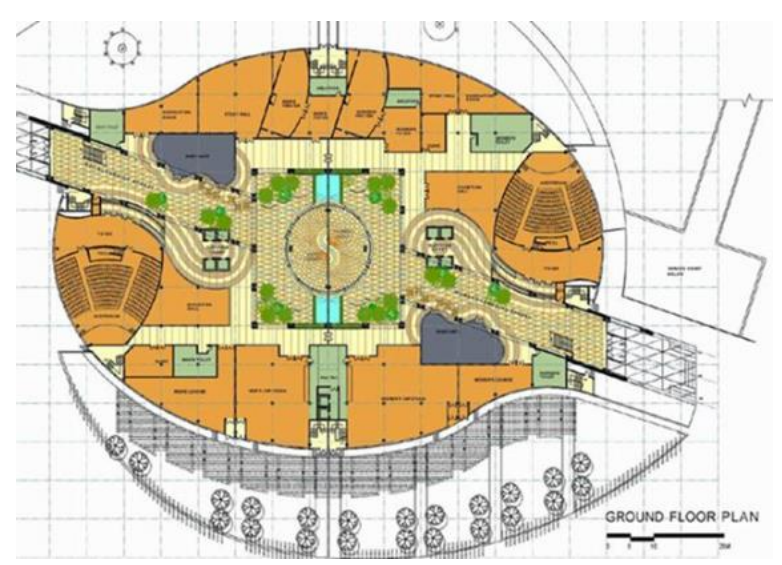

Figure 12. CIT's Ground floor plan (picture from Nader Ardalan) 
The courtyard is the only element that has been repeated in Ardalan's projects regardless of their programs. The reasons behind this repetition might be related to the environmental situation or the importance of natural light for Ardalan. The point which is important for consideration is how the form and function of courtyard has changed during the time in his projects. The courtyard is a traditional principle and in Ardalan's most recent projects, he tried to exploit it in different ways to more appropriately suit contemporary architectural perfection. In the CIT the atrium around the central core with its glass cap represents the idea of courtyard which brings natural light in the middle of the mass (fig. 13).

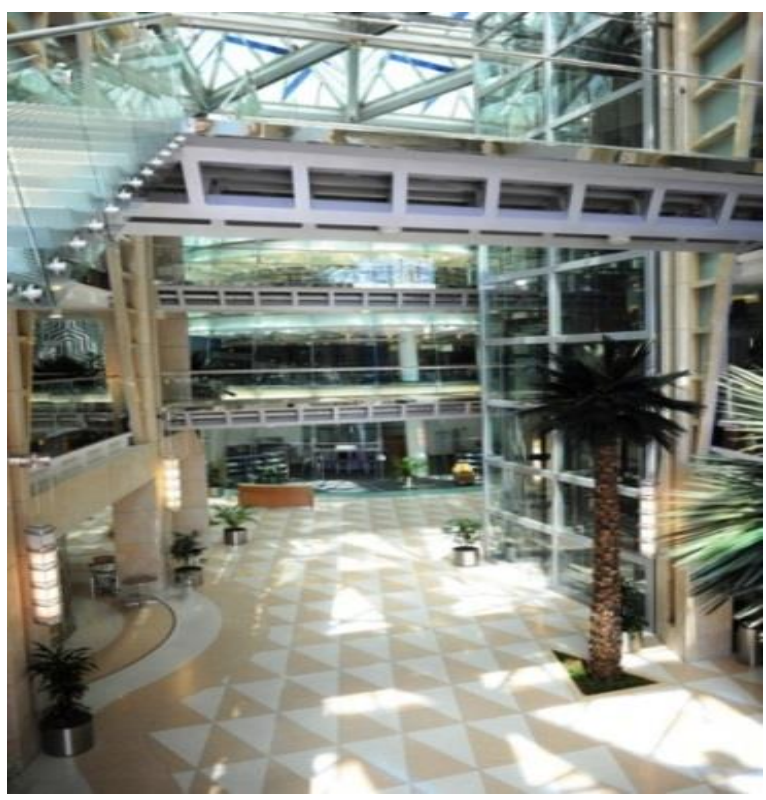

Figure 13. Natural lighting in the courtyard (picture from University of Al-Ain)

\section{Ideas of Sense of Unity and the CIT}

The idea of centrality which is acknowledged in the Sense of Unity can be seen in this project as well as all other ones. The most important idea is related to the concept of centrality. From a sophist perspective a central point of a circle is symbolic of the Divine manifestation at a timeless moment. In the CIT the concept of centrality appears on both a small and a large scale. Centrality is in square and circle inherently which are used in floor plans. In addition, regardless of individual character of circle and square in the CIT, the main geometric shapes are arranged simply to convey the concept of centrality. The core of the building is a circle which is surrounded by a square and then followed by an oval (deformed circle). These geometric shapes are concentric (fig. 14).

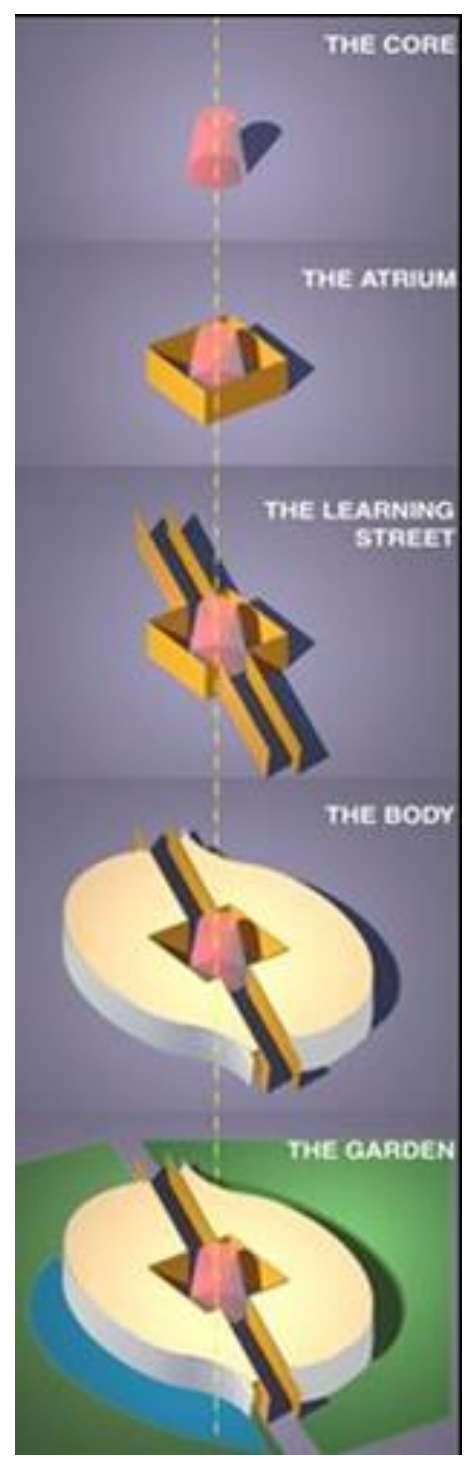

Figure 14. Idea of centrality in the CIT (picture from Nader Ardalan

Technology helped Ardalan in this regard. For instance, in the ICMS the forms of units around the courtyard are octagon. While in Ardalan's drawings their primary forms are circular. It seems due to technical forces Ardalan had to modify the circle to the most possible form which is an octagon. However in the CIT he was able to create a circular core using wide expanses of glass.

Not only the concept of centrality is emphasized by the geometry but also the same line of thinking can be seen in the function of the spaces. The core is used as the network server center of the IT College it means this core is the heart of the college. In addition the landscape and more importantly the pattern of the roof emphasizes the centrality and intention of the designer as well. The roof is covered by colorful glass where a circle in the middle of a square is shown (fig. $15)$. 


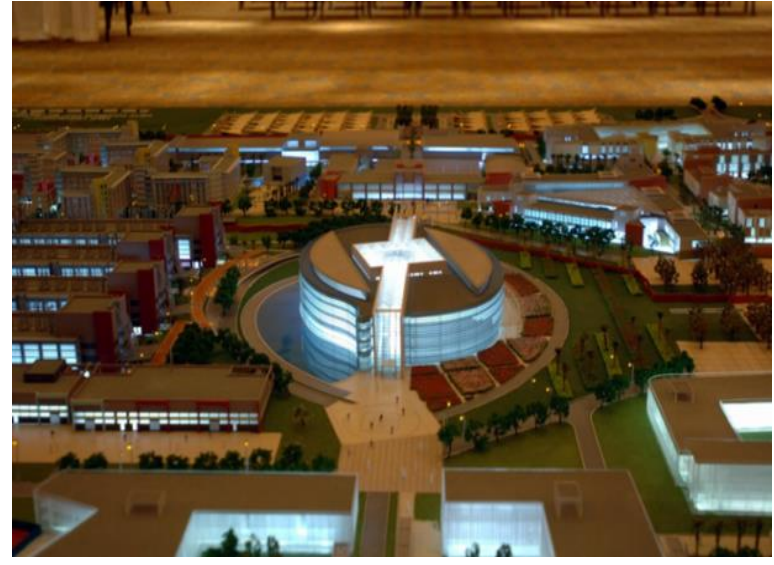

Figure 15. CIT (picture from University of Al-Ain)

Another idea of Sense of Unity that can be identified in this project relates to Sufi doctrine regarding the universe. The universe contains the macrocosm and the microcosm and two motions are assumed in these two realms toward the Divine. This concept was also used in the ICMS where inwardlooking symbolizes an inward direction toward the hidden treasure that is the seat of Divine spirit (microcosm). And outward-looking symbolizes looking towards the enveloping heavens (macrocosm). In the CIT the pathway may symbolize the microcosm as it begins from the outside and goes toward the core or the center, thus suggesting the center represents the seat of Divine. Interestingly, the pattern on the roof shows two ways from outside toward the middle of the square. In fact, this is the reflection of the ground level pathway. Consequently the width of the pathway and also its reflection on the roof pattern demonstrate Ardalan's intention for crystalizing the concept of microcosm and macrocosm.

\section{CONCLUSION}

Ardalan states that all projects after 1970 were influenced by his new understanding of Islamic architecture. In this view, the ICMS can be nominated as the first project which is clearly impacted by the ideas discussed in Sense of Unity's. Ardalan in two different interviews has introduced this project as the first test case in conjunction with Sense of Unity although he has not discussed in more detail (Haeri, 1991; Badshah, 1991). The ICMS applies many ideas and concepts which are discussed in Sense of Unity. From a critical point of view, this project has three considerable features in comparison with his other projects; first the amount of gnostic ideas coming from Sense of Unity such as zahir and batin, microcosm and macrocosm motions, centrality, unity and multiplicity and the circle of existing. It seems
Ardalan was keen to raise his new theoretical attitude as much as possible in this project. Second, the way in which these concepts are conveyed is simplistic. In fact Ardalan had not enough experience in that time to use more artistic or complicated instruments. Third, there are some clear similarities between the geometry and setting of buildings in the ICMS and specific traditional Iranian complexes. This level of similarity has never been repeated in Ardalan's other projects.

The CIT seems similar to the contemporary architecture of the Gulf region which is called 'modern'. However Ardalan has tried to implement his understanding of Islamic architecture in different ways. And different programs or structures have not stopped him to expressing Sense of Unity's ideas in his projects

After the ICMS, Ardalan's approach became more moderate and stable project after project. In other words the ICMS does not look modern and its appearance tried to faithfully implement traditional forms, however in other projects architectural features and structural systems are often in conjunction with modern architecture, while they are still affected by conceptual principles of Islamic Architecture. Ardalan's works demonstrate that Ardalan's attitude has evolved to express Islamic and a traditional sense in architecture. Bringing a traditional theme through patterns which is unprecedented in Ardalan's projects is a bit superficial in comparison with other traditional concepts that normally can be found in the first generation of his projects. It seems that his clients' attitudes or the market expectation changed in 1990s. On the other hand geometry and some traditional concepts still can be seen in his most recent projects in the same line of thinking. This line of thinking should be analysed in the light of ideas of Sense of Unity

In fact, after the ICMS, Ardalan tried to enrich his modern knowledge with his gnostic view and conceptual principles of Islamic architecture. While Ardalan is emphasizing the concept of centrality, he applied a high level of technology in construction. This trend is continued in the Tehran Contemporary Museum; the Bu Ali Sina University with its unusual dome; the ADMA Tower and eventually it culminated in the College of Information Technology in Alain. Ardalan could professionally express conceptual principles of his understanding of traditional Islamic architecture through the contemporary style and high technology. As a result while this college seems a modern building, it conveys Sense of Unity's ideas without the simplification that is evident in the ICMS. $^{\text {vi }}$ 


\section{ACKNOWLEDGEMENT}

Special thanks to Mr. Nader Ardalan, Professor Stanislaus Fung, Professor Samer Akkach and Mrs. Helen Farrell for their friendly support.

\section{REFERENCES}

Akkach, S. (1990). The Sacred Pattern of Traditional Islamic Architecture According to Sufi Doctrine. $\mathrm{Ph} . \mathrm{D}$, University of Sydney.

Akkach, S. (2005). "The Poetics of Concealment: alNabulusi's Encounter with the Dome of the Rock". Muqarnas, 22, p. 110-127.

Ardalan, N. (1980). "The Visual Language of Symbolic Form: A Preliminary Study of Mosque Architecture". In: Katz., J. G. (ed.) In Architecture as Symbol and Self-Identity. Philadelphia: Aga Khan Award for Architecture.

Ardalan, N. (1989). "ICMS Architect's Records". In: Architecture, T.A.K.A.F. (ed.).

Ardalan, N. (2002). "Eternal Simplicity: Information Technology College, Al Ain, UAE; Architects: KEO International Consultants". Architecture Plus: Architecture of a New World, p. 46-51.

Ardalan, N. (2009). "Spiritual Duets". 2A, p. 11-15.

Ardalan, N. \& Bakhtiar, L. (1973). The Sense of Unity: The Sufi Tradition in Persian Architecture. Chicago: University of Chicago Press.

Ardalan, N. (2013). E-mail message to author, June 12

Ardalan, N. (2014). E-mail message to author, January 12

Badshah, A. (1991). "A Fusion of Nature and Culture in Design (interview with Nader Ardalan)". Mimar, 40(4).

Bolkhari, H.G. (2005). "Sheikh Akbar and Sheikh Ahmad". Andishe Dini, p. 135-151.

Critchlow, K. (1976). Islamic Patterns: an Analytical and Cosmological Approach. New York, Schocken Books.

Fung, S. (1982). Undergraduate Papers. Bachelor, University of Sydney.

Haeri, S. (1991). Interview with Nader Ardalan. Boston: Foundation for Iranian Studies Program of Oral History.

Kassarjian, J.B. \& Ardalan, N. (1989). "The Iran Centre for Management Studies, Tehran". Mimar, p. 22-39.
Nasr, S.H. (1973). Introduction to the Sense of Unity: The Sufi Tradition in Persian Architecture, by Nader Ardalan and Laleh Bakhtiar. Chicago: University of Chicago Press.

Masud, A.B. (2009). Iranian Contemporary Architecture, an Inquiry into Tradition and Modernity. Tehran, Honare Memari.

Snodgrass, A. (1990). Architecture, Time and Eternity: Studies in the Stellar and Temporal Symbolism of Traditional Buildings. New Delhi, P.K. Goel for Aditya Prakashan.

\section{Notes:}

${ }^{\mathrm{i}}$ Microcosm in fact in Islamic notions means the smallest universe in contrast to Macrocosm which means the largest universe. Additionally in Sufi's doctrine and especially Ibn Arabi's perspective, the concept of macrocosm refers to an outward motion to the Divine and microcosm represents an inward motion to hidden treasure that is the seat of Divine both are ascending motion in the same level of worthiness. There are light differences regarding these concepts for example Sarhandi argued that these motions cannot cover Divine as Divine is beyond of macrocosm and microcosm. Therefore these motions cannot be endless and they are confined. Moreover macrocosm has a priority over microcosm. In other words macrocosm is a substantial basis for microcosm. Bolkhsri, H.G. 2005. Sheikh akbar and Sheikh ahmad. Andishe Dini, p. 135-151.

ii The zahir is the sensible form... which emphasizes the quantitative aspect which is most readily comprehensible.

iii The batin is essential or qualitative aspect which all things possess.

iv The numbers of sources concerning the nine projects are not considerable. With the exception of a few articles written by Ardalan about his projects, the majority of the texts are based on his interviews. The limited number of sources may not be sufficient to analyse Ardalan's design work. To resolve this lack of access to documents, I have visited six of his projects in the Middle East to provide visual documentation using photography, floor plans and sections that form part of the contribution to my thesis. These projects have never been studied in relation to each other and more importantly they have not analysed to from Sense of Unity's point of view.

${ }^{\mathrm{v}}$ In addition they symbolise the beginning point of the universe as: "everything begins with divine essence, the creation of the world begins with the intellect or the pen, the spatial formation of human body begins with the sacrum and the construction of the corporeal domain of heaven and earth begins with the rock which is the sacrum of the cosmic formation, so likewise the laying out of traditional Islamic buildings, cities and gardens begins with the establishment of the centre." Akkach, S. 1990. The Sacred Pattern of Traditional Islamic Architecture According to Sufi Doctrine. Ph.D, University of Sydney.

vi This trend can be seen from a sophistic view, poetry from Rumi says: I was raw, I was cocked, and I was burnet. 